\title{
Effective Organization Management in Multinational Corporations: In the Context of Collectivism and Individualism
}

\author{
Yuxin Xie ${ }^{1 *}$,Zixiang Lou ${ }^{1}$ \\ ${ }^{1}$ Faculty of liberal Arts and professional Studies, B.A., Economics York University Toronto Canada. \\ ${ }^{1}$ British International Course Center, Guangzhou Province, Guangzhou, 510000, China. \\ *Corresponding author.Email: Yuxin xie-iamjessicaxie@gmail.com
}

\begin{abstract}
Companies are growing at a rapid pace these days, and economies are becoming increasingly globalized. A growing number of businesses are expanding internationally. Those businesses aren't the same as traditional businesses. They had to deal with cross-cultural issues that traditional businesses would never have to deal with, necessitating the development of new solutions. This research uses corpus analytical tools to conduct a content analysis of existing crosscultural issues such as language barriers, differences in employee values and personalities, and attitudes toward work. This research involves cultures from all over the world, including Arabic, Central African, Latin American, and Southern European cultures. People from different cultures will think in different ways, and the formation of these mental circuses will be determined by where they have lived and worked, as well as where they grew up. The study uses the example of a Canadian manager working in South America who has differing ideas from others in the South American branch company. Accents, the way we talk, and the media we use all have an impact on a company's productivity, according to the findings. People's values and personalities are influenced by the cultures in which they grow up.The companies where they used to work would affect employees' attitudes toward work.
\end{abstract}

Keywords: Obstacle, Management, Multinational company, Barrier.

\section{INTRODUCTION}

Within the past years, before the pandemic, take 2019 as an example. More than 327 big cross-cultural companies shut down. $30 \%$ of them were valued at over 100 million. Aside from the fanatical factors in the companies, the human factors are worth digging further. Matching values and unifying behaviors are fundamental and necessary for a cross-cultural organization. These can ensure that company can make a common goal and process normally. Besides, basic rules can measure whether the company can keep working effectively.

In the United States, workplaces are increasingly diverse. While there are many benefits associated with a culturally diverse workplace, there are particular challenges this environment presents. Katie Reynold, from Hult International Business School, identifies challenges associated with culturally diverse work environment, such as negative stereotypes can interfere in the integration of multicultural teams, professional communication can be misunderstood or misinterpreted across cultures and languages, professional etiquette can vary across cultures, and conflicting working styles across teams [1].

So this study is to point out the general problems that cross-cultural businesses are going to face, including linguistic differences in cross-cultural business, personalities of employees from different cultural backgrounds, and attitudes of workers toward jobs and their work styles. During the process of digging further, some convincible examples are listed, so that readers can simply understand how the problems form, and easily see problems roots. After this, the study tries to find solutions that can fill the gap. According to each problem's root, we find several relatively effective ways to solve the problems. Hence, those businesses can have sustainable development. This study might improve methods for cross-cultural companies to make good use of the employees' personalities, develop better communication, and stimulate employees in many different aspects. 


\section{DIFFERENCES BETWEEN MULTINATIONAL COMPANIES}

In the context of multinational corporations, different employees have different personalities and work attitudes.

In the context of the current globalization of the world, globalized trade exchanges are becoming more frequent. More and more companies will consider setting up their own companies abroad and hiring local employees to fully understand the foreign market and develop a broader sales area. Under the premise of increasing the market share based on the foundation, the company will develop and upgrade products suitable for the local area through the establishment of branches in foreign countries, as well as do market research and market development. This requires corporate management to effectively manage the different personalities and work attitudes of different employees, to effectively promote and develop foreign companies. Based on the two organizational environments of collectivism and individualism, this article analyzes the background of differences in personalities and work attitudes of employees in corporate organizations under different cultures.

\subsection{Differences in Language of Employees Based on Multinational Companies}

The increase in language diversity and differences in organizations is a product of globalization. Nowadays, it is a common phenomenon for employees of multinational companies to communicate with colleagues of different languages every day. For employees of multinational companies, due to differences in regions, there may be different native speakers. Therefore, language barriers may be caused by the communication of various employees and various departments. This prevents employees from correctly expressing their ideas and suggestions. And knowledge sharing is an important part of communication between organizations. Moreover, at the organizational level, the sharing and exchange of information is an important part of organizational culture, which plays an important role in the development and promotion of organizational performance. Even if a multinational company establishes its business overseas, it will still need cultural and information exchanges between organizations so that it can promote the development of the business. Therefore, in the context of globalization, language differences among employees of multinational corporations are a common phenomenon.

In a company with language differentiation, employees will face some obstacles. For example, when the leader is a non-local person, if he cannot communicate with local employees, he will be unable to communicate effectively with employees to a greater extent. Therefore, under normal circumstances, for multinational companies, hiring a bilingual leader can effectively reduce some of the obstacles.

\subsection{Based on the Background of Personality Differences of Different Employees}

Personality is a general and distinctive pattern in how a person reacts to and interacts with others. In the global context, people's personalities will be different. This paper will be based on the research of scholars [2] to explore the differences of personality in the context of China and South America. The big five personality traits allow different people's personalities to be defined and understood. The Big Five model suggests classifying or group personalities. The original model was proposed by Ernest Tupes and Raymond Christal in 1961, but it was not accepted by academia until the 1980s. And scholars proposed "many personality psychologists have reached a consensus that five personality constructs, referred to as the Big Five, are necessary and sufficient to describe the basic dimensions of normal personality."[4] The theory establishes five factors: extraversion (outgoing/energetic vs. $\quad$ solitary/reserved), agreeableness (friendly/compassionate vs. critical/rational), openness to experience (inventive/curious vs. consistent/cautious), conscientiousness(efficient/ organized vs. extravagant/careless) and neuroticism (sensitive/nervous vs. resilient/ confident). Currently, the Big Five model is widely used to test personality traits, based on the context of cross-cultural and multinational companies. In the other cross-cutting models of the Big Five model In cultural studies, it is found that the open factor is not very robust, even if it is defined as one of the five universal factors[3]. The definition of openness may be different in different regions, such as collectivism in China. Individualism in America and the Americas will affect the personality characteristics and deviations of different people. Based on regional differences, The Chinese Personality Assessment Inventory (CPAI: Cheung et al., 1996) originated from a collaborative project between the Chinese University of Hong Kong and the Institute of Psychology of the Chinese Academy of Sciences. The purpose of the project is to develop culturally-related multidimensional personality through the use of mainstream psychological science methods. The comprehensive personality structure set of this research provides a basis for testing the personality structure of Chinese people [2]. When managing the employees of multinational companies, business managers should analyze and manage their personalities based on different regional differences. The development of personal Righteousness and collectivism will lead to different character outcomes. As Yang[2]put forward, in the individualistic culture, the willingness of individual orientation is more obvious and developed in the collective, and the views of different employees are more differentiated. But in a collectivist culture, social orientation will affect individual characteristics and make 
decisions. This means that in the organization of a collective society, personality characteristics will be more biased towards group cognition, lacking a certain degree of differentiation.

\subsection{Differences in Work Attitudes of Employees Under Different Backgrounds}

Work attitude is one of the elements of a person's job evaluation, which constitutes the employee's feelings, beliefs and persistence to work. It is how employees feel about different aspects of the work environment. Among them, job satisfaction and organizational commitment are two key attitudes related to important results. In the general environment, employees with different cultural backgrounds may have different working attitudes towards work. From a major research initiative, entitled culture leadership and organizations: The GLOBAL study of 62 societies, contributes to the development and verification of theories related to the cultural contingencies of leadership [4]. The theory divides the organization into two groups, one is The "Southern Asian cluster" which incorporates Thailand, India, Indonesia, Iran, Philippines and Malaysia. The 'Anglo cluster' incorporates Australia, Canada, Ireland, New Zealand, South Africa, United Kingdom and the United States . Groups are analyzed according to the classification of collectivist and individualist countries. Scholars [5] believe that if the results of individual countries are analyzed for differences in work attitudes, then crosscultural comparisons are rare.

Therefore, for collectivist countries such as Malaysia, when their corporate organizations conduct team management, employees will put the needs and benefits of the group in the organization before their own needs. In collectivism, decision-making is based on group consensus, even if there are a few different ideas. Participants also follow the mentality of the minority subordinate to the majority. In contrast, Australia's individualism is more pronounced, with data showing[6]that Australia has a score of 90 for individualism, second only to the United States. Regarding the collectivist organization environment in Malaysia, individual attitudes have a lot to do with the organization. Moreover, in a collectivist environment, the concept of class is also deeply ingrained [5]. Incorporate managers, the tasks of the superiors will be more dominant. Therefore, in this type of organization, leadership is more necessary. Level of external stimulus to stimulate employees' ideas. Like Australia, where individualism is more dominant, this management structure means more flattening. Every employee can put forward his indirection, and employees will also try to express themselves Personal decisions. This unique cultural difference will affect the attitudes of employees in different organizations to the workplace, and the desire for promotion is very different. Therefore, analyzing the attitudes of employees under different backgrounds can be derived from collectivism and individualism, Individualistic employees are more self-motivated and creative, they are willing to put forward their ideas and are willing to act. However, employees under collectivism have a deeper level of autonomy, and they are more inclined to rely on the overall interests of the team to propose solutions Way, personal thoughts will be weakened.

\section{OBSTACLES FACED BY MULTINATIONAL COMPANIES}

\subsection{Language Barrier in Multinational Companies}

Language barriers are a common challenge in international business settings, and a two-way process. What native speakers often don't realize is that frequently it is not the other person's accent but their own way of speaking that creates the greatest barriers to effective communication. Both workers and managers need to solve the problems out. There are several ways to settle this dispute.

The first thing that a company needs to do is unifying a common language. Nowadays in the international society, the most common ones are English and French. There are two benefits. First, say more by saying less. the same language can speed up tasks' assignment and tasks' accomplishment. Second, it can improve the productivity. Managers are enhancing comprehension while using a collectively understood language, which fuels trust and efficiency. When managers eliminate ambiguity, employees can proceed confidently with a task rather than spend time trying to decipher the underlying meaning[11]. However, when manager is going to unify the language, international worker will suffer a lot, because they need to study a bran-new linguistic system and start to get into a strange culture. The best way for managers is to build up small groups, which contain about five to seven people, in the company. Each group should contain native speakers and international workers, and the native speakers need to take the great present in there so that each group of five to seven people doesn't break up into any smaller linguistic groups. After this, international workers will have a wonderful environment to develop their language skills. It might take a long time, but it is worthy.

Moreover, managers need to speak slowly and clearly. Even if managers are pressured for time, don't rush through communication especially when managers are going to assign tasks. Doing so often takes more time, as miscommunication and misunderstanding can result, and managers will eventually have to spend additional time in clearing up the confusion. Defining the basics like special terms of business before people proceed with their work. In international business contexts terms such as: 
'success', 'doneness', 'meetings', 'punctuality', may mean different things to different people. Spend some time at the start of your communication defining what these terms mean to you and others. Invest in building a shared vocabulary[12]. If managers forget to define terms, or do not notice that he is speaking too fast, which always happens, sitting down and listening to workers' excuses are quite necessary. Listening to workers' excuses, which cannot be counted as a waste of time or something is formalism, is a good way for a manager to rethink his behaviors. If managers do make such mistakes, changes and apologies are necessary. But if they don't, managers can take that as a warm tip. Of course, connivance with excuses can lead to bad results, such as laxity about people's work, so some regulations are necessary to limit the formation of excuses.

Furthermore, the media that we choose is quite significant. In some circumstances, managers have to communicate with their people face to face especially when managers are going to be reasonable to employees or give psychological counseling for employees. Sending emails or make a phone call might be useless in this situation. However, sometimes, managers have to send messages to employees if there is an emergency. Be mindful not to 'overuse' email. While useful, there are times when the medium is likely to be ineffective. When a message is complex and complicated or there is tension or conflict that needs to be resolved, switch to another medium.

\subsection{Multinational Companies can Pass Regular Values Training}

At the macro level, the company's overall leadership and micro governance, changes in personal thinking and concepts)

For companies, at a macro level, they can train their employees on values for the overall development of the company. One can introduce the company's development in a transnational context and the company's internal values when new employees are recruited, which will help employees understand the company in a diverse environment. This can help employees do their work better. Regular cultural values training for employees can be done through weekly or monthly meetings. The regular expression of values by the leadership can awaken employees' awareness of the company's values and development. The alignment of employees and organizational values will also encourage better communication and coordination within the organization, which can help employees meet organizational needs. On the other hand, it will also improve the performance of employees and make them more clear about their work tasks[7]. A suitable company values will give employees more satisfaction at work and allow them to better understand their job responsibilities.

\subsection{Multinational Companies can Adopt Effective Incentive Policies to Target Diverse Employee Structures}

Motivation is a very important factor for all employees. Employee motivation is one of the managers' policies to improve the effective work management of employees in the organization. The report also pointed out that incentives will make the organization more successful, because motivated employees will continue to seek improved practices to complete their work. For employees to be effective. In the context of multinational organizations, incentives will be analyzed through the analysis of companies in a collectivist environment and companies in individualism.

For collectivist multinational companies, companies under the background of collectivism pay more attention to the overall interests of the team. The characteristic of collectivism is to combine individuals through a strict social framework and divide individuals into groups within and outside groups. Individuals show a high degree of loyalty to the inner group and expect the inner group to take care of them[8]. For employees in the context of collectivism, they have high collectivist values, and they will strive to more actively internalize corporate requirements and emotional performance rules, because their personal values are more likely to be matched for the overall benefit of the team. Therefore, for collectivist teams, it is more inclined to use incentive policies under the hierarchy to divide employees into different teams. Motivate employees in each team by motivating between teams. The formation of hierarchical small teams can effectively motivate employees. Therefore, when multinational companies are set up under the background of collectivism, they can achieve a high level of performance through competition among teams.

For the employees of multinational companies in the context of individualism, they have more personal opinions and ideas and dare to express their ideas, as long as they think their opinions can be explained. Markus and Kitayama[9] argue that differences in selfconstruction, for example, individualism have several consequences for understanding one's motivations. Therefore, we expect individualism to affect employee motivation. Also, for individuals with independent selfconstruction, people are usually motivated by certain internal and individual rooted needs (for example, fulfillment needs, self-actualization motivation[9]. According to previous theories [10], when personal standards or goals are compared with the feedback received about the individual's performance in these goals and standards, discrepancy detection occurs. This is the key operation of self-regulation Therefore, feedback seeking allows employees to collect key information about their behavior and performance related to their goals, and when differences are found, their behavior can be changed to reduce the difference between 
goals and performance. Leaders should pay more attention to their personal performance development and viewpoints for such employees. For example: Formulate more personalized incentive policies for the development of employees. At the beginning of the year, different employees will discuss their career development and work attitudes personally, so that the management can more effectively recognize the employee's motivation framework and understand how to more effectively motivate employees with different personalities.

\section{CONCLUSION}

This paper is based on the current situation of the continuous development of globalization. In order to open up the global market, more and more companies choose to set up their own companies in foreign countries, trying to expand their sales and market shares. This paper firstly summarizes the background of language differences, personality differences and work attitude differences that multinational companies have in setting up companies in foreign countries, and states the current situation faced by multinational companies in today's globalized market. Then, it elaborates on the obstacles to the development of multinational corporations under the current background, and explains the main difficulties that multinational corporations need to face from language barriers, barriers of different values and barriers of different working styles. Finally, from the three obstacles, the methods that can be used to deal with it and the effective management measures that can be implemented in the development of multinational enterprises in the future are proposed in turn.

The final conclusion is that, in order to allow multinational companies to manage their companies more effectively, the following three measures have been drawn: unifying the global communication language and setting a unified global language such as English, regular value training for employees, and appropriate incentive policies.

This paper mainly analyzes the background of companies and organizations setting up branches abroad, the obstacles they may encounter and how to deal with these obstacles. However, there is still a lack of practical cases in this paper. In future studies, in-depth discussions can be made on how to efficiently operate enterprises in collectivist countries and individualistic international organizations through real transnational enterprises. Future research will focus more on the process and mechanism of managing internal operations of multinational enterprises.

\section{ACKNOWLEDGMENT}

First and foremost, I would like to express my deep and sincere gratitude to my research supervisor, Peter J. Robertson , for giving me the opportunity to do research and providing invaluable guidance throughout this research. His vision, motivation and dynamism have deeply inspired me. He taught me a good overview of key factors that influence interpersonal behavior in organizations. These include individual characteristics including personality, values, and motivations, as well as organizational features including reward systems, group dynamics, and organizational culture. It was a great chance and honor to work and study under his guidance. I grateful for what he offered me through online. I would also like to thank him for his friendship and great sense of humor. a good overview of key factors that influence interpersonal behavior in organizations. These include individual characteristics including personality, values, and motivations, as well as organizational features including reward systems, group dynamics, and organizational culture.

\section{REFERENCES}

[1] By Ivana Fisic, February 9th, 2021. How to overcome cultural and language barriers in the workplace https://clockify.me/blog/managing-teams/culturaland-language-barriers-at-work/ .

[2] Cheung FM;van de Vijver FJ;Leong FT; (n.d.). Toward a new approach to the study of personality in culture. The American psychologist.

[3] Triandis, H. C., \& Suh, E. M. (2002). Cultural influences on personality. Annual Review of Psychology, 53, 133-160.

[4] House, R., Hanges, P., Javidan, M., Dorfman, P., \& Gupta, V. (2004). Culture, Leadership, and Organizations The GLOBE study of 62 Societies. California: Sage Publications Inc.

[5] Wood, Glenice J., and Uma D. Jogulu. "Malaysian and Australian Male and Female MIDDLE Managers: A Cross-Cultural Comparison of WORKPLACE Attitudes, Aspirations for Promotion, AND Self-Rated Leadership Styles." The International Journal of Knowledge, Culture, and Change Management: Annual Review, vol. 6, no. 3, 2006, pp. 109-120.

[6] Hofstede, G., Hofstede, G.J. (2005), Cultures and Organizations: Software of the Mind, 2nd ed., McGraw Hill, New York, NY, .

[7] Lin, Y.-C., Yu, C. and Yi, C.-C. (2014). The effects of positive affect, person-job fit, and well-being on job.

[8] Lee, M. (2019a). Relationship Bonds and Service Provider's Emotional Labor: Moderating Effects of Collectivism. 
[9] Markus, H.R. and Kitayama, S. (1991) Culture and the Self: Implications for cognition, emotion, and motivation. P.

[10] Brutus, S., \& Greguras, G. J. (2008). SelfConstruals, Motivation, and Feedback-Seeking Behaviors. International Journal of Selection and Assessment, 16(3), 282-291.

[11] Mac McIntire, June 3rd 2014. How to Overcome Language and Cultural Barriers in the Workplace https://www.linkedin.com/pulse/2014060314320620499125-how-to-overcome-language-andcultural-barriers-in-the-workplace.

[12] Kate Berardo. 10 Strategies for Overcoming Language

Barriers http://www.europarc.org/communicationskills/pdf/10\%20Strategies\%20for\%20Overcoming $\%$ 20Language\%20Barriers.pdf. 